\begin{tabular}{lc|c|}
\hline Bentham open & The Open Dentistry Journal & $\begin{array}{l}\text { The } \\
\text { Open Dentistry } \\
\text { lournal }\end{array}$ \\
\hline CrossMark & Content list available at: www.benthamopen.com/TODENTJ/ & DOI: $10.2174 / 1874210601610010079$ \\
\hline
\end{tabular}

\title{
Changes in the Oral Moisture and the Amount of Microorganisms in Saliva and Tongue Coating after Oral Ingestion Resumption: A Pilot Study
}

Natsuki Kishimoto ${ }^{1}$, Roxana Stegaroiu, ${ }^{2, *}$, Satoko Shibata ${ }^{2}$, Kayoko Ito $^{3}$, Makoto Inoue ${ }^{4}$ and Akitsugu Ohuchi ${ }^{5}$

${ }^{I}$ Doctor's Program of Oral Health and Welfare, Niigata University Graduate School of Medical and Dental Sciences, Niigata, Japan

${ }^{2}$ Department of Oral Health and Welfare, Division of Oral Science for Health Promotion, Niigata University Graduate School of Medical and Dental Sciences, Niigata, Japan

${ }^{3}$ Oral Rehabilitation, Niigata University Medical and Dental Hospital, Niigata, Japan

${ }^{4}$ Department of Oral Health Science, Division of Dysphagia Rehabilitation, Niigata University Graduate School of Medical and Dental Sciences, Niigata, Japan

${ }^{5}$ Department of Oral Health and Welfare, Division of Welfare, Niigata University Graduate School of Medical and Dental Sciences, Niigata, Japan

\begin{abstract}
:
Background and Objective:

Tube feeding has been significantly associated with a higher rate of aspiration pneumonia that is mainly related to oral microorganisms and a reduced salivary flow. Thus, the difference in the mode of nutritional intake is expected to affect the oral environment, but this has not yet been fully clarified. The purpose of this study was to investigate, in tube-fed patients, changes in the oral moisture and the counts of microorganisms in saliva and tongue coating, which occur after oral ingestion resumption.
\end{abstract}

\section{Methods:}

Study participants were 7 tube-fed inpatients of the Niigata University Medical and Dental Hospital ( $72.7 \pm 8.5$ years old) who received dysphagia rehabilitation at the Unit of Dysphagia Rehabilitation until oral ingestion resumption. Their oral health, swallowing, and nutrition status, oral mucosal moisture, amount of unstimulated saliva and the counts of microorganisms (total microorganisms, streptococci, Candida) in saliva and tongue coating were investigated and compared before and after the recommencement of oral intake.

\section{Results:}

Tongue coating, choking, oral mucosal moisture and amount of unstimulated saliva were improved significantly after resumption of oral ingestion. The other investigated parameters did not significantly change, except for the streptococci in tongue coating, which significantly increased 1 week after oral ingestion recommencement, but decreased thereafter.

\section{Conclusion:}

After oral intake resumption, oral mucosal moisture and amount of unstimulated saliva were improved. However, because of a transitory increase in the counts of streptococci with oral ingestion recommencement, it is important to appropriately manage oral

\footnotetext{
* Address correspondence to this author at the Division of Oral Science for Health Promotion, Niigata University Graduate School of Medical and Dental Sciences, 2-5274, Gakkocho-dori, Chuo-ku, Niigata City, 951-8514 Japan; Tel: +81-25-227-0547; Fax: +81-25-227-0547; E-mail: roxana@dent.niigata-u.ac.jp
} 
hygiene in these patients, according to the changes in their intraoral microbiota.

Keywords: Dysphagia, dysphagia rehabilitation, oral ingestion resumption, oral microorganisms, oral mucosal moisture, unstimulated saliva.

\section{INTRODUCTION}

In a rapidly aging society, pneumonia, a common infection in the elderly, is a serious disease leading to high hospitalization and mortality rates [1]; in Japan, pneumonia has been reported as the third cause of death in 2011 [2]. Aspiration pneumonia, a form of pneumonia caused by oropharyngeal content aspired into the lower respiratory tract, has a high incidence, especially in hospitalized and institutionalized persons and is associated with high mortality rates $[1,3,4]$. In the United States, the number of aspiration pneumonia cases have been estimated to be as high as 200,000 per year with over 15,000 deaths per year [4]. About 60 percent of the hospitalized pneumonia patients suffer from aspiration pneumonia [5], which is mainly associated with microorganisms that colonize the human oral cavity [4, 6, 7]. Both medical and dental staffs that provide care to older adults have been equally concerned about the consequences of dysphagia and recognize the importance of a good oral hygiene and oral health care in the prevention of aspiration pneumonia [8 - 13]. In addition to oral care, the role of dysphagia training has been also reported to contribute to the prevention of aspiration pneumonia $[8,13]$.

Langmore et al. [1], has evaluated the specific risk factors for the development of aspiration pneumonia and revealed that tube feeding was significantly associated with a higher rate of aspiration pneumonia. Tube feeding has been also found to promote colonization of the oropharynx with bacterial pathogens, in part, because in tube-fed patients there is no food or liquid to stimulate saliva production, which in turns leads to a reduction of salivary flow [1, 3]. Thus, the difference in the mode of nutritional intake is expected to affect the oral environment, but this has not yet been fully clarified. Therefore, the purpose of this study was to investigate the changes after oral ingestion resumption in the oral moisture and counts of microorganisms of saliva and tongue coating in a group of tube-fed patients to whom oral health care and dysphagia rehabilitation has been provided.

\section{MATERIALS AND METHODOLOGY}

\section{Study Participants}

Eleven inpatients of Niigata University Medical and Dental Hospital who were referred to the Unit of Dysphagia Rehabilitation between September 2011 and December 2012 gave their written informed consent to participate in the study. Whenever necessary, written informed consent was also received from the family member who was their legal guardian. The study was reviewed and approved by the Ethics Committee of Niigata University Faculty of Dentistry (Approval Number: 23-R18-11-09).

At the initial visit at the Unit of Dysphagia Rehabilitation, the subjects were all tube-fed for at least one week (from one week to four months). Patients who were administrated antibacterial medicine systemically or medicines with dry mouth side effect at any time during the study were excluded. Therefore, from an initial number of 11 patients who agreed to participate, only 7 (4 males and 3 females, mean age $72.7 \pm 8.5$ years) completed the study. The age, sex, and primary disease of the subjects by the time of referral to the Unit of Dysphagia Rehabilitation are shown in Table 1.

Table 1. Subject age, sex, and primary disease of the subjects by the time of referral to the Unit of Dysphagia Rehabilitation.

\begin{tabular}{|c|c|c|c|}
\hline Subject ID & Age & Sex & Primary disease \\
\hline 1 & 69 & F & Hemorrhagic duodenal ulcer \\
\hline 2 & 74 & M & Meningioma \\
\hline 3 & 77 & F & Myasthenia gravis \\
\hline 4 & 86 & M & Meningioma \\
\hline 5 & 78 & M & Stroke \\
\hline 6 & 68 & M & Acoustic neurilemoma \\
\hline 7 & 57 & F & usingis \\
\hline
\end{tabular}

At the initial visit, the ingestion function was examined in all the patients, using the assessment sheet of the Unit of Dysphagia Rehabilitation, videoendoscopy and videofluoroscopy. Based on the results of these examinations, 6 out of the 7 patients were diagnosed with dysphagia and the dentists in charge prescribed dysphagia rehabilitation as direct 
and/or indirect therapy that was provided by dentists of the Unit of Dysphagia Rehabilitation or by a dental hygienist (N.K.), following dentist instructions. The direct therapy consisted in oral intake of gelatin jelly or pasted food in gradually increasing amounts, according to the patients swallowing abilities. The indirect therapy consisted in head elevation and laryngeal range of motion exercises, as well as stretching of the suprahyoid muscles. Dysphagia rehabilitation was administrated for approximately 1 month on average (range: 10 days-2 months). The number of dysphagia therapy sessions per subject was approximately 12 on average (range: 2-30). The patient evaluated as apt to start oral feeding right after the first examination did not receive dysphagia rehabilitation.

The oral health care of the subjects was managed by the dentist in charge of each patient and 1 dental hygienist (N.K.). At the beginning, all subjects received professional oral health care 1-5 times a week, depending on the patient condition. This consisted in professional full mouth tooth cleaning, using tooth brushes, dental floss, and interdental brushes; cleaning of the oral mucosa and tongue by sponge brushes and, in denture patients, denture cleaning by denture brushes. The routine oral care (tooth brushing and cleaning of the oral mucosa by a sponge brush) was performed in the hospital ward by nurses, whenever it was necessary to assist or complement patient self-care. However, after oral intake was resumed, the subjects restarted oral self-care, and became all independent of oral care by the time they were able to have regular meals. Oral self-care had been encouraged by the dental professionals in charge of the patients, since dependency on others for oral care has been reported to be a strong predictor for aspiration pneumonia [1]. Oral hygiene instructions were given and patient self-care effectiveness was assessed as part of the oral examinations throughout the study. The denture patients were instructed to brush their dentures and keep them in a denture cleanser solution, when not worn. Before denture wearing resumption, the dentures were ultrasonically cleaned in a sodium hypochlorite solution by the dental hygienist.

In the present study, oral intake was considered to be resumed, if the patient could swallow at least a spoonful of jelly or pasted food during the direct therapy. If the patient was able to have 3 regular meals a day, meals were considered to be resumed. The time point of meal resuming was decided by the dentist or physician in charge of each patient.

\section{Table 2. Parameters investigated and evaluation method.}

\begin{tabular}{|c|c|c|}
\hline Category & Evaluated item & Evaluation method \\
\hline \multirow{12}{*}{ Oral health status } & Cleanliness & \multirow{6}{*}{ Screening sheet (Table 3 ) } \\
\hline & Dryness & \\
\hline & Tongue coating & \\
\hline & Tooth brushing (self-care) & \\
\hline & Breath odor & \\
\hline & Gums, oral mucosa, and tongue troubles & \\
\hline & Use of dentures & Presence or absence \\
\hline & Amount of unstimulated saliva & The 30 seconds cotton roll method \\
\hline & Oral mucosal moisture & Moisture Checker for Mucus $^{\circledR}$ \\
\hline & \multirow{3}{*}{ Microorganisms } & Total microorganism counts \\
\hline & & Streptococci counts \\
\hline & & Candida counts \\
\hline \multirow{5}{*}{ Swallowing status } & Tongue protrusion & \multirow{5}{*}{ Screening sheet (Table 3 ) } \\
\hline & Cheek puffing test & \\
\hline & Articulation & \\
\hline & Oral intake & \\
\hline & Choking & \\
\hline \multirow{3}{*}{ Nutrition status } & Period of tube feeding & \multirow{6}{*}{ The patient records } \\
\hline & Period to meal resumption & \\
\hline & Diet form & \\
\hline \multirow{3}{*}{ General condition } & Body temperature & \\
\hline & Activities of daily living (ADL) & \\
\hline & Japan Coma Scale (JCS) & \\
\hline
\end{tabular}

\section{Methods of Investigation}

In each subject, the following parameters were investigated: oral health and nutrition status, amount of unstimulated 
saliva, oral mucosal moisture, and counts of microorganisms in saliva and tongue coating (Table 2). The saliva and tongue coating samples of each subject were taken and the measurements of oral mucosal moisture were performed by 1 investigator (N.K.) at the onset of each dysphagia therapy and professional oral cleaning sessions, which were performed after at least 60 minutes from the mouth cleaning, in the patients who performed self-care, and after at least 60 minutes from food or beverage intake, in the patients in whom oral intake was resumed [14]. The sampling and measurements were continued until the time of discharge: on average, 22 days (7- 45 days) from regular meal resumption.

\section{Oral Health, Swallowing and Nutrition Status}

The oral health status and presence of choking were screened and scored, using a screening sheet modified from Tsukada et al. [15] (Table 3), which was developed based on the Oral Health Assessment Tool by Chalmers et al. [16] to which categories of swallowing assessment had been added. The modifications consisted in the omission of 3 assessment categories from Tsukada et al. screening sheet (periodontal tissue condition, presence of caries, and denture problems, which did not make the object of this study), and the addition of a subcategory to the tongue coating evaluation (the assessment of tongue surface was added to the thickness assessment in the original sheet). Each category was investigated by predefined criteria of judgment for 3 levels and rated by a score from 0 to 2 (Table 3 ). In the category "Tongue coating", 1 point was added to the score, if the coating was spread over two third of the tongue or more. The system score was an addition made to the screening sheet of Tsukada et al., to enable comparison of the oral condition throughout the study period. The score system was adopted from Chalmers et al. [16]: score 0 corresponded to a healthy condition, score 1 to changes, and score 2 to an unhealthy condition. However, one category in Tsukada $e t$ al. screening sheet, "Presence of dentures" with the three levels: "Upper denture present", "Lower denture present", "No dentures", did not fit to the newly introduced score system, and thus, in this study, the presence or absence of dentures was investigated and recorded on a separate sheet at the initial visit, together with other information on the subject condition that was retrieved from the patient records on each investigation day: the body temperature, activities of daily living (ADL) and Japan Coma Scale (JCS).

Table 3. Criteria of judgment of the oral health and swallowing status (modified from Tsukada et al. 2012).

\begin{tabular}{|c|c|c|c|}
\hline Category & Score 0 & Score 1 & Score 2 \\
\hline $\begin{array}{l}\text { Oral cleanliness } \\
\text { (denture included) }\end{array}$ & $\begin{array}{l}\text { Good: Clean and no } \\
\text { food particles or tartar } \\
\text { in mouth or dentures }\end{array}$ & $\begin{array}{c}\text { Fair: Food particles/ tartar/ plaque } \\
\text { in some areas of the mouth or } \\
\text { dentures }\end{array}$ & $\begin{array}{c}\text { Poor: Food particles/tartar/ plaque } \\
\text { covering most areas of the mouth or } \\
\text { dentures }\end{array}$ \\
\hline Dryness of the mouth (by visual inspection) & $\begin{array}{l}\text { Not present: Moist } \\
\text { tissues, free flowing } \\
\text { saliva }\end{array}$ & $\begin{array}{l}\text { Present to a certain extent: sticky } \\
\text { tissues, little saliva present }\end{array}$ & $\begin{array}{l}\text { Present: Tissues parched and red, } \\
\text { very little/no saliva present }\end{array}$ \\
\hline Tongue coating & Not present & \begin{tabular}{|c|} 
Thin coating present: \\
Covering less than $2 / 3$ of the tongue \\
surface, (if covering $2 / 3$ or more: +1 \\
point)
\end{tabular} & \begin{tabular}{|} 
Thick coating present: \\
Covering less than $2 / 3$ of the tongue \\
surface, (if covering $2 / 3$ or more: \\
+1 point)
\end{tabular} \\
\hline Tooth brushing (oral self-care) & Possible & Aid needed & Impossible \\
\hline Breath odor (as perceived during conversation) & No bad breath & Bad breath can be identified & Severe halitosis (bad breath) \\
\hline Gums and oral mucosa troubles & $\begin{array}{l}\text { Not present: Pink, } \\
\text { moist, smooth, no } \\
\text { bleeding }\end{array}$ & $\begin{array}{l}\text { Present (slight): Dry, shiny, rough, } \\
\text { red swollen, one ulcer/sore spot }\end{array}$ & $\begin{array}{c}\text { Present (severe): Swollen, bleeding, } \\
\text { ulcers, white/red patches, } \\
\text { generalized redness }\end{array}$ \\
\hline Tongue troubles & $\begin{array}{l}\text { Not present: Pink, } \\
\text { moist, papillae present }\end{array}$ & $\begin{array}{l}\text { Present (slight): No papillae, red, } \\
\text { shiny }\end{array}$ & $\begin{array}{l}\text { Present (severe): } \\
\text { blistery, fissured }\end{array}$ \\
\hline Tongue protrusion beyond the lower lip & Possible & $\begin{array}{c}\text { Tongue protrusion cannot surpass } \\
\text { the lower lip }\end{array}$ & Impossible \\
\hline $\begin{array}{l}\text { Cheek puffing test (Closing the lips and puffing } \\
\text { out the cheeks) }\end{array}$ & Possible & Incomplete closing of lips & Impossible \\
\hline $\begin{array}{c}\text { Articulation } \\
\text { (Pronounce "Pa-n-da-no-ta-ka-ra-mo-no") }\end{array}$ & Possible & Unclear & Impossible \\
\hline Oral intake (from patient records) & $\begin{array}{l}\text { Possible (3 meals per } \\
\text { day) }\end{array}$ & $\begin{array}{l}\text { Partially possible ( } 1 \text { meal per day or } \\
\text { just some spoonfuls) }\end{array}$ & Impossible (tube feeding) \\
\hline Choking (patient-reported) & Never & Sometimes & Often \\
\hline
\end{tabular}

In addition, data on the subjects' nutrition status (period of tube feeding, period to meal resumption, diet form) were collected from the patient records. After ingestion resumption, information on the diet form (paste, soft, or solid) was 
additionally collected.

\section{Amount of Unstimulated Saliva}

An absorbent method, the 30 seconds cotton roll method $[17,18]$ was used to measure the unstimulated salivary amount. One cotton roll (DENTAL COTTON ROLL ${ }^{\circledR}$, No. 3, Hakujuji Co., Ltd., Japan) was introduced in a zip bag and weighed on an electronic scale, before and after it was placed sublingually for 30 seconds. The unstimulated salivary amount was expressed as the difference in weight between the 2 measurements.

\section{Oral Mucosal Moisture}

The oral mucosal moisture was investigated with an oral moisture checking device called "Moisture Checker for Mucus $^{\circledR} "$ (Life Co. Ltd, Tokyo, Japan), which was developed to indirectly measure the moisture content in the oral mucosa based on the capacitance method [19 - 21]. The probe tip of the device, covered by a disposable sensor cover, is pressed against the mucosal surface and measures the capacitance (electrostatic capacity) between the poles of the probe, which is proportional to the dielectric constant; and this, in turn, has a positive correlation with the content of moisture. Thus, the readings of the device are relative values without units, which correlate with the oral mucosal water content [19 - 21]. Following the manufacturer instructions, measurements were repeated 3 times per session and the median value was chosen and recorded for the buccal mucosa, reportedly the most reliable among oral measurement sites [19]. The oral mucosa was considered as "dry", if the value recorded was less than 28, and as "not dry", if the value was 28 or more, according to the guidelines reported by Yamada et al. [19].

\section{Counts of Microorganisms in Saliva and Tongue Coating}

For microorganism counts, unstimulated saliva was collected with a sterile cotton swab that was successively placed for 5 seconds bilaterally in the oral vestibule and floor of the mouth posterior regions. Tongue coating samples were collected, following the method described by Nishiyama et al. [22] by swabbing over the center of the tongue with a sterile cotton swab. The original method was slightly modified by increasing the swabbing time from 5 to 10 times. Particular care was given to keep the pressure of swabbing constant at approximately $20 \mathrm{~g}$ [23].

All samples were transported in sterilized vials with tight, screw-on caps, under anaerobic condition, and transferred within several minutes to an anaerobic glove box containing $80 \%$ nitrogen, $10 \%$ hydrogen, and $10 \%$ carbon dioxide. While in the box, each sample was suspended in $1.0 \mathrm{ml}$ sterile solution of $40 \mathrm{mM}$ potassium phosphate (pH 7.0$)$ and 1 mM EDTA, and dispersed with a glass homogenizer. After serial 10-fold dilution with the same buffer, $0.1 \mathrm{ml}$ aliquots of each dilution were spread on surfaces of triplicate brain heart infusion (BHI) broth, Mitis-Salivarius (MS) plates and Sabouraud agar. Then, the BHI broth and MS plates were incubated in the anaerobic glove box, at $37^{\circ} \mathrm{C}$ for one week, to investigate the counts of total microorganisms and streptococci, respectively. Plates, media, buffer solution and experimental instruments were kept in the box, for at least 24 hours before use. The Sabouraud agar samples were also incubated aerobically in air containing $30 \%$ carbon dioxide and then microaerophilically under $5 \%$ oxygen with $80 \%$ nitrogen, $7.5 \%$ carbon dioxide and $7.5 \%$ hydrogen, at $37^{\circ} \mathrm{C}$ for one week to investigate the counts of Candida [24].

In all the samples, total counts of colony-forming units (CFU) were determined as CFU/ml. Streptococci and Candida were identified on Gram's staining.

\section{Data Analysis}

For each numerical parameter, the measurements before and after the recommencement of oral intake were statistically compared with $p$ values of $<0.05$ considered to be statistically significant. The scores for oral health and swallowing status by each category were analyzed using Mann-Whitney U test. The amount of unstimulated saliva, oral mucosal moisture and counts of microorganisms in saliva and tongue coating were each analyzed using Wilcoxon signed-rank test. In case a significant difference was found, the measurements of microorganism counts were analyzed in more detail, by comparing the data at 4 time points, to find out when the change occurred: before starting direct therapy, just before meal resumption, 1 week after meal resumption, and at discharge (Kruskal-Wallis test).

\section{RESULTS}

\section{Oral Health, Swallowing and Nutrition Status}

Among the oral health and swallowing categories screened, the amount of tongue coating $(P=0.03)$ and choking 
$(P=0.007)$ significantly decreased after oral intake resumption. The other investigated categories were initially in good condition and did not change over time.

The nutrition status of each patient is shown in Table 4. At discharge, all subjects were able to eat again 3 meals per day without choking; diet form was solid in 1 subject, soft in 4 , and paste in 2.

Table 4. Subjects' nutrition status.

\begin{tabular}{|c|c|c|c|}
\hline Patient ID & Period of tube feeding (days) & Period to meal resumption (days) & Diet form at discharge \\
\hline 1 & 120 & 10 & Soft \\
\hline 2 & 7 & 30 & Solid \\
\hline 3 & 30 & 30 & Soft \\
\hline 4 & 10 & 10 & Paste \\
\hline 5 & 7 & 7 & Paste \\
\hline 6 & 7 & 20 & Soft \\
\hline 7 & 7 & 45 & Soft \\
\hline Mean \pm SD & $26.86 \pm 41.93$ & $21.71 \pm 13.98$ & \\
\hline
\end{tabular}

\section{Amount of Unstimulated Saliva}

The amount of unstimulated saliva significantly increased between the investigated time points $(P=0.03)$ (Fig. 1).

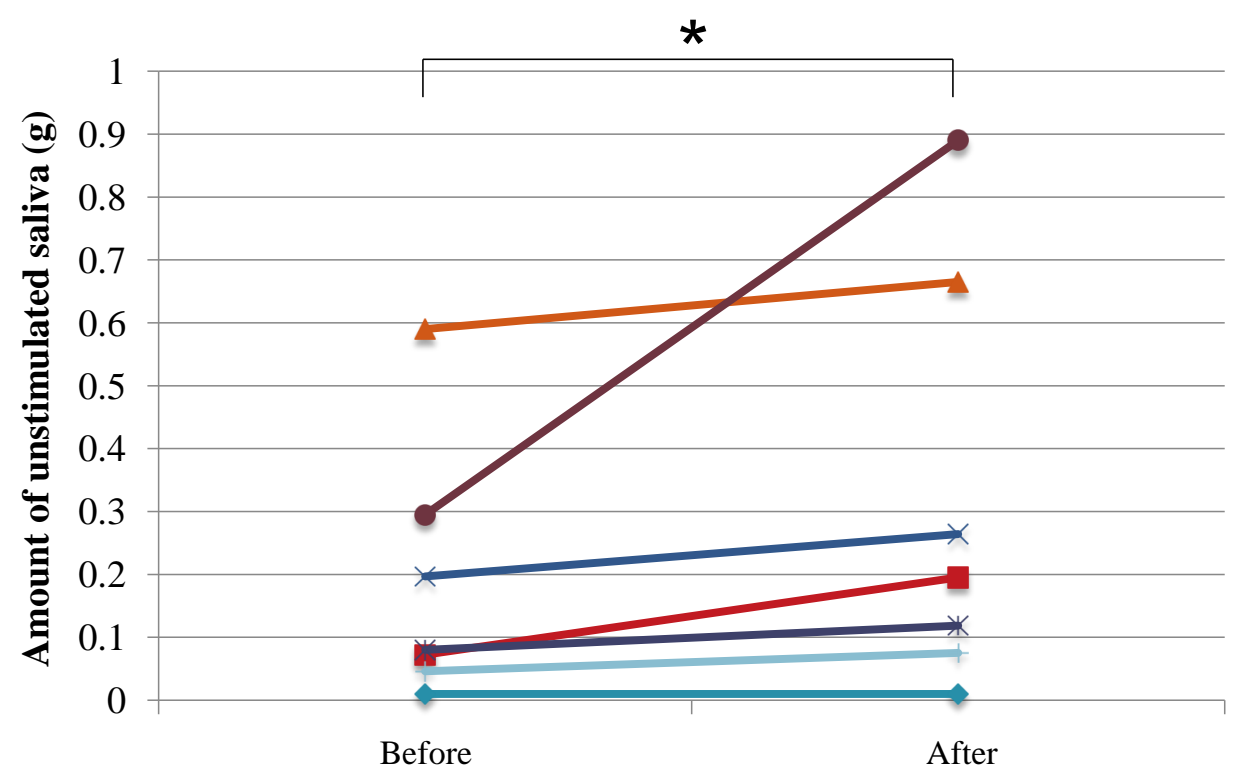

Resumption of oral ingestion

Fig. (1). Amount of unstimulated saliva in each subject before and after resumption of oral ingestion $(\mathrm{n}=7)$; asterisk $(*)$ indicates significant difference (Wilcoxon signed-rank test; $P=0.03$ )

\section{Oral Mucosal Moisture}

One subject kept wearing a mask during the study to alleviate the oral dryness symptoms. Since mask-wearing has been reported to be effective in improving oral moisture (Yoshii S, 2010, abstract presented at the $16^{\text {th }}$ Annual Meeting of the Japanese Society of Dysphagia, 2010, Sep 3-4; Niigata, Japan), the data of this subject were excluded from the analysis of the oral mucosal moisture.

Comparison of the data before and after resumption of oral ingestion showed that moisture content of the oral mucosa significantly increased $(P=0.03)$ after resumption of oral ingestion, and, consequently, all subjects showed values equivalent to the "not dry" condition at that time point (Fig. 2). 


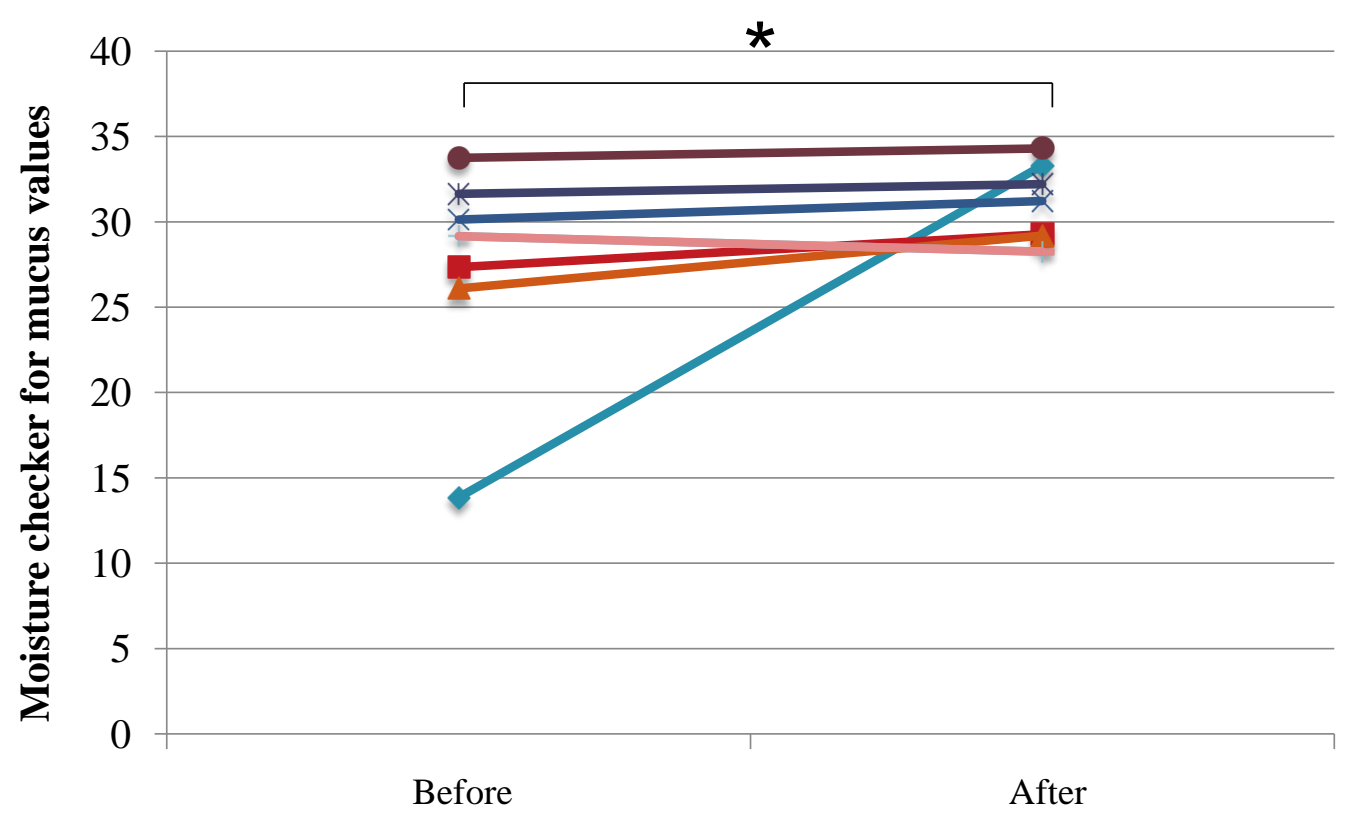

Resumption of oral ingestion

Fig. (2). Oral mucosal moisture in each subject before and after resumption of oral ingestion ( $\mathrm{n}=6$, one mask-wearing subject was excluded from measurements); asterisk $\left(^{*}\right)$ indicates significant difference (Wilcoxon signed-rank test; $P=0.03$ ).

\section{Counts of Microorganisms in Saliva and Tongue Coating}

Because of a handling mistake, the counts of Candida from the tongue coating of 1 subject were not available for measurements, and thus, in the analysis of the tongue coating Candida, the sample number was 6.

The counts of Candida and total microorganisms in saliva and tongue coating, as well as streptococci in saliva did not change significantly between the time points before and after oral intake resumption $(P>0.05)($ Table 5). On the other hand, the counts of streptococci in tongue coating were significantly increased after, as compared with before, oral intake resumption $(P=0.03)$ (Table 5).

Table 5. The mean counts of total microorganisms, streptococci, and Candida in saliva and tongue coating before and after resumption of oral ingestion.

\begin{tabular}{|c|c|c|c|c|c|c|}
\hline \multirow{2}{*}{ Counts } & \multicolumn{3}{|c|}{ Saliva } & \multicolumn{3}{|c|}{ Tongue coating } \\
\cline { 2 - 7 } & $\begin{array}{c}\text { Before } \\
(\mathrm{CFU} / \mathrm{ml})\end{array}$ & $\begin{array}{c}\text { After } \\
(\mathrm{CFU} / \mathrm{ml})\end{array}$ & P value & $\begin{array}{c}\text { Before } \\
(\mathrm{CFU} / \mathrm{ml})\end{array}$ & $\begin{array}{c}\text { After } \\
(\mathrm{CFU} / \mathrm{ml})\end{array}$ & P value \\
\hline Total microorganisms & $3.9 \times 107$ & $6.1 \times 107$ & 0.89 & $1.2 \times 108$ & $6.4 \times 108$ & 0.23 \\
\hline Streptococci & $1.8 \times 107$ & $6.5 \times 107$ & 0.33 & $1.9 \times 107$ & $3.0 \times 108$ & $0.03 *$ \\
\hline Candida & $4.5 \times 103$ & $2.6 \times 102$ & 0.54 & $5.8 \times 102$ & $6.0 \times 102$ & 0.97 \\
\hline
\end{tabular}

Asterisk $(*)$ indicates significant difference (Wilcoxon signed-rank test; $P<0.05$ )

When compared among 4 time points, the counts of streptococci in tongue coating, were significantly increased 1 week after oral ingestion recommencement, as compared with the time point just before meal resumption, but tended to decrease thereafter to a level comparable with the initial one (Fig. 3 ).

\section{DISCUSSION}

Amount of tongue coating and choking were significantly improved after recommencement of oral intake. The decrease in the amount of tongue coating could have been caused by both oral cleaning performed throughout the study and improvement of self-cleaning function associated with oral ingestion resumption that triggered an increased salivary flow and enabled the mechanical cleaning by food (especially fibrous or high water-content food). The 
decrease of choking, and the significant improvement in the nutrition status (oral ingestion resumption with meals of consistencies ranging from paste to solid at time of discharge), could have been caused by the professional dysphagia rehabilitation, as well as the recovery from the systemic disease that had made eating impossible.

Moreover, the dysphagia rehabilitation by dental professionals not only played a role in the recovery of oral ingestion at the time of tube withdrawal, but also helped in the oral moisture improvement and remission of choking. In tube-fed patients, lack of jaw and lip movements has been suggested to cause oral dryness [25]. Thus, the increases of oral mucosal moisture found in the present study after oral intake resumption may have been caused by the enhancement of the perioral muscle activity and an increase in their frequency of use after meal resumption. Furthermore, with oral intake resumption, the ingestion amount of liquids and high moisture containing food gradually increased, and that presumably enhanced the salivary flow and oral moisture. In addition, the removal of the nasogastric feeding tube facilitated nasal breathing with subsequent remission of oral breathing, which in turn might have contributed to the increase in oral moisture content. Moreover, our findings suggest that the reduction in salivary flow and oral mucosal moisture during tube feeding is rather transitory, and that most patients improve salivary flow and reach normal levels of oral mucosal moisture after a mean period of 22 days (7- 45 days) after recommencement of oral ingestion.

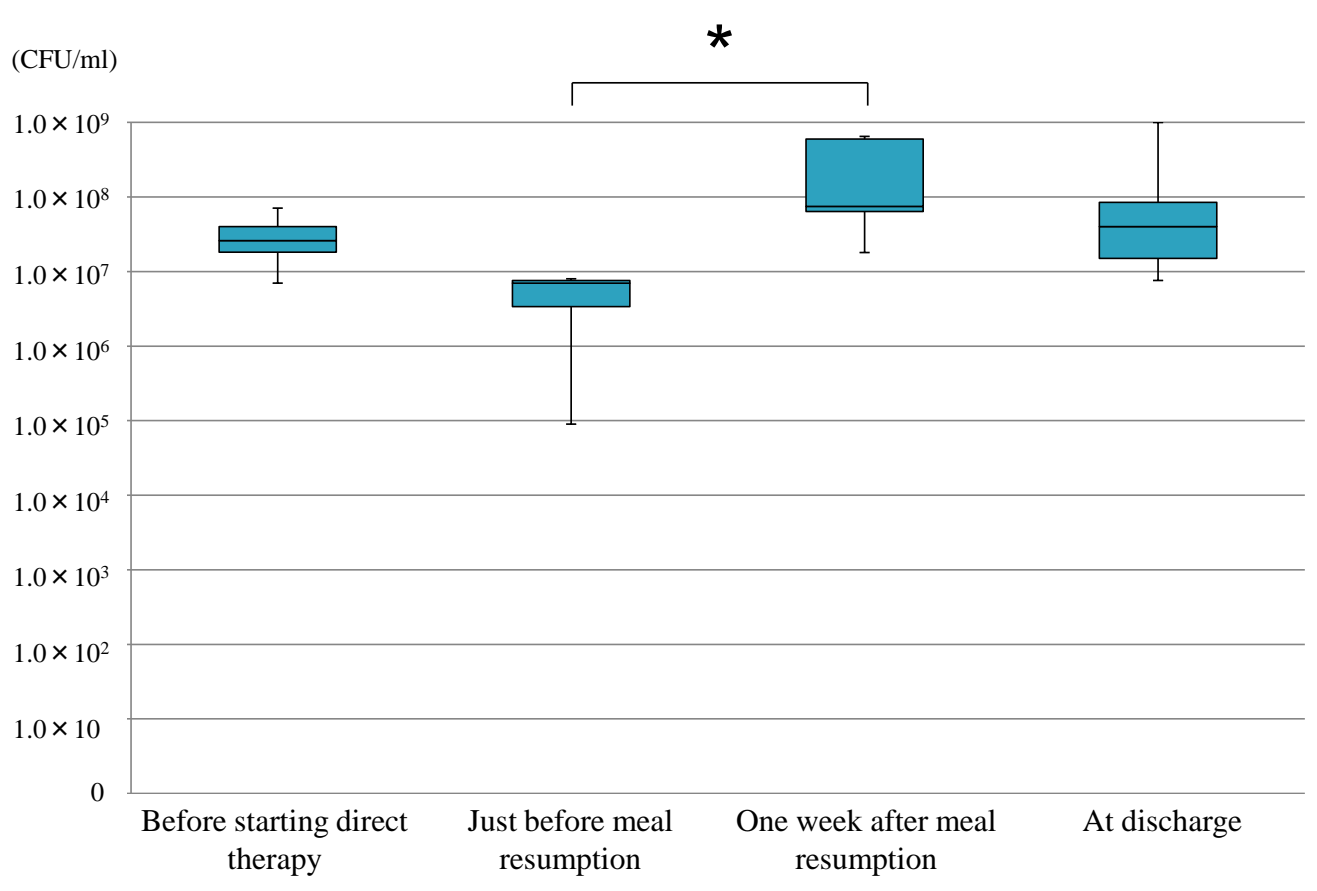

Fig. (3). Mean values and standard deviations of the counts of streptococci in tongue coating at different time points $(n=7)$; asterisk $(*)$ indicates significant difference (Kruskal-Wallis test; $P=0.04$ ).

Except for streptococci in the tongue coating, the counts of microorganism in saliva and tongue coating did not change significantly between the time points before and after oral intake resumption. Thus, for most regions of the mouth, despite the use of a feeding tube, which is reportedly related with increased counts of microorganisms [1, 3], good oral cleanliness was maintained during the study, by gradually changing the oral hygiene plan from professional to assisted cleaning, and, by the time of food intake recommencement, to self-care. However, in the tongue coating, an increase in streptococci counts was found after resumption of food intake. When compared among the 4 time points, the counts of streptococci in tongue coating were significantly increased only between the first week after and the time point just before oral ingestion recommencement. This increase was probably caused by the intake of food containing carbohydrates, which are important constituents for Streptococcus species growth [26]. This particular result suggests that more thorough oral hygiene measures, under the instructions of dental professionals, and including careful cleaning of the dorsum of the tongue, are needed in the period that immediately follows oral ingestion resumption, to reduce the 
risk of caries formation in dentate patients. Furthermore, streptococci counts in the tongue coating by the time of discharge were decreased to a level comparable with the initial one. That could have been the result of the oral hygiene implementation by dental professionals and oral self-care enhancement made possible by the improvement of the subject general condition through a better nutrition. Moreover, meal resumption gradually led to higher salivary secretion, as well as fluid and alimentary fiber ingestion, which are considered to be involved in the self-cleaning function of the oral cavity.

Although the results of this pilot study are promising, further clinical studies of large sample size are needed to fully clarify the changes occurring after oral ingestion resumption in the oral environment with special emphasis on the intraoral microbiota.

\section{CONCLUSION}

Within the limitations given by the small number of participants in this pilot study, our findings suggest that resumption of oral ingestion after tube feeding is accompanied by changes in some parameters of the intraoral environment: unstimulated saliva secretion and oral mucosal moisture were significantly increased; while a transitory increase in tongue coating streptococci was observed in the first week after tube feeding withdrawal. Because of this transient increase, it is important to appropriately manage oral hygiene in these patients, according to the changes in their intraoral microbiota.

\section{CONFLICT OF INTEREST}

The authors confirm that this article content has no conflict of interest.

\section{ACKNOWLEDGEMENTS}

We appreciate the guidance received during the study from Dr. Hiroyuki Uematsu, from the Division of Microbiology and Infectious Diseases, Niigata University Graduate School of Medical and Dental Sciences. We are also grateful to the dental staff of the Oral Rehabilitation Clinic and Unit of Dysphagia Rehabilitation, Niigata University Medical and Dental Hospital, for their cooperation throughout the study.

This study was presented in part at the International Symposium on Human Resource Development towards Global Initiative, Cha-am, Thailand, February 17, 2013.

\section{REFERENCES}

[1] Langmore SE, Terpenning MS, Schork A, et al. Predictors of aspiration pneumonia: how important is dysphagia? Dysphagia 1998; 13(2): 69-81.

[http://dx.doi.org/10.1007/PL00009559] [PMID: 9513300]

[2] Ministry of Health. Labour and Welfare Japan. Available from: http://www.mhlw.go.jp/english/database/db-hh/1-2.html 2011. [Accessed on: 18 March 2013].

[3] Langmore SE, Skarupski KA, Park PS, Fries BE. Predictors of aspiration pneumonia in nursing home residents. Dysphagia 2002; 17(4): 298-307.

[http://dx.doi.org/10.1007/s00455-002-0072-5] [PMID: 12355145]

[4] Pace CC, McCullough GH. The association between oral microorgansims and aspiration pneumonia in the institutionalized elderly: review and recommendations. Dysphagia 2010; 25(4): 307-22. [http://dx.doi.org/10.1007/s00455-010-9298-9] [PMID: 20824288]

[5] Teramoto S, Fukuchi Y, Sasaki H, Sato K, Sekizawa K, Matsuse T. Japanese Study Group on Aspiration Pulmonary Disease. High incidence of aspiration pneumonia in community- and hospital-acquired pneumonia in hospitalized patients: a multicenter, prospective study in Japan. $\mathrm{J}$ Am Geriatr Soc 2008; 56(3): 577-9.

[http://dx.doi.org/10.1111/j.1532-5415.2008.01597.x] [PMID: 18315680]

[6] Scannapieco FA, Mylotte JM. Relationships between periodontal disease and bacterial pneumonia. J Periodontol 1996; 67(Suppl. 10): 1114-22. [http://dx.doi.org/10.1902/jop.1996.67.10s.1114] [PMID: 8910830]

[7] Okuda K, Kimizuka R, Abe S, et al. Involvement of periodontopathic biofilm in respiratory infections. J Periodontol 2005; 76(Suppl. 11): 2154-60.

[http://dx.doi.org/10.1902/jop.2005.76.11-S.2154] [PMID: 16277588]

[8] Kikawada M, Iwamoto T, Takasaki M. Aspiration and infection in the elderly : epidemiology, diagnosis and management. Drugs Aging 2005; 22(2): 115-30.

[http://dx.doi.org/10.2165/00002512-200522020-00003] [PMID: 15733019] 
[9] Yoneyama T, Yoshida M, Ohrui T, et al. Oral care reduces pneumonia in older patients in nursing homes. J Am Geriatr Soc 2002; 50(3): 430-3. [http://dx.doi.org/10.1046/j.1532-5415.2002.50106.x] [PMID: 11943036]

[10] van der Maarel-Wierink CD, Vanobbergen JN, Bronkhorst EM, Schols JM, de Baat C. Oral health care and aspiration pneumonia in frail older people: a systematic literature review. Gerodontology 2013; 30(1): 3-9. [http://dx.doi.org/10.1111/j.1741-2358.2012.00637.x] [PMID: 22390255]

[11] Adachi M, Ishihara K, Abe S, Okuda K. Professional oral health care by dental hygienists reduced respiratory infections in elderly persons requiring nursing care. Int J Dent Hyg 2007; 5(2): 69-74. [http://dx.doi.org/10.1111/j.1601-5037.2007.00233.x] [PMID: 17461957]

[12] Sue Eisenstadt E. Dysphagia and aspiration pneumonia in older adults. J Am Acad Nurse Pract 2010; 22(1): 17-22. [http://dx.doi.org/10.1111/j.1745-7599.2009.00470.x] [PMID: 20074192]

[13] Ueda K, Yamada Y, Toyosato A, Nomura S, Saitho E. Effects of functional training of dysphagia to prevent pneumonia for patients on tube feeding. Gerodontology 2004; 21(2): 108-11. [http://dx.doi.org/10.1111/j.1741-2358.2004.00016.x] [PMID: 15185991]

[14] Edgar WM, Dawes C, O’Mullane DM, Eds. Saliva and oral health. $3^{\text {rd }}$ ed. London: British Dental Association 2004.

[15] Tsukada S, Shibata S, Kajii Y, et al. Investigation of screening sheet for multiple-professional use to judge necessity for dental intervention in inpatients: Considerations based on comparison of screening results by dentist and dental hygienist. J Jpn Soc Dent Hyg 2012; 7: 43-54.

[16] Chalmers JM, King PL, Spencer AJ, Wright FA, Carter KD. The oral health assessment tool--validity and reliability. Aust Dent J 2005; 50(3): 191-9. [http://dx.doi.org/10.1111/j.1834-7819.2005.tb00360.x] [PMID: 16238218]

[17] Ichikawa K, Sakuma S, Yoshihara A, et al. Relationships between the amount of saliva and medications in elderly individuals. Gerodontology 2011; 28(2): 116-20. [http://dx.doi.org/10.1111/j.1741-2358.2009.00358.x] [PMID: 20545772]

[18] Funayama S, Ito K, Nohno K, et al. Comparative study of salivary secretion in cotton roll method and spitting method. Niigata Dent J 2008; 38: 37-43.

[19] Yamada H, Nakagawa Y, Nomura Y, et al. Preliminary results of moisture checker for mucus in diagnosing dry mouth. Oral Dis 2005; 11(6): 405-7. [http://dx.doi.org/10.1111/j.1601-0825.2005.01136.x] [PMID: 16269034]

[20] Ishimoto S, Tsunoda K, Fujimaki Y, et al. Objective and non-invasive evaluation of dry mouth. Auris Nasus Larynx 2008; 35(1): 89-93. [http://dx.doi.org/10.1016/j.anl.2007.05.002] [PMID: 18037254]

[21] Fukushima Y, Yoda T, Kokabu S, et al. Evaluation of an oral moisture-checking device for screening dry mouth. J Stomatology 2013; 3: 440-6. [http://dx.doi.org/10.4236/ojst.2013.38073]

[22] Nishiyama Y, Inaba E, Uematsu H, Senpuku H. Effects of mucosal care on oral pathogens in professional oral hygiene to the elderly. Arch Gerontol Geriatr 2010; 51(3): e139-43. [http://dx.doi.org/10.1016/j.archger.2010.04.009] [PMID: 20494464]

[23] Hisano A, Kikutani T, Tashiro H, et al. The effect of sampling pressure applied to the tongue on bacterial counts. Ronen Shika Igaku 2009; 24: $354-9$.

[24] Hori R, Sato M, Kohno S, et al. Tongue microflora in edentulous geriatric denture- wearers. Microb Ecol Health Dis 1999; 11 : 89-95. [http://dx.doi.org/10.1080/089106099435826]

[25] Ogasawara T, Andou N, Kawase S, et al. Potential factors responsible for dryness of the dorsum of the tongue in elderly requiring care. Gerodontology 2008; 25(4): 217-21

[http://dx.doi.org/10.1111/j.1741-2358.2007.00213.x] [PMID: 18380781]

[26] Moye ZD, Zeng L, Burne RA. Fueling the caries process: carbohydrate metabolism and gene regulation by Streptococcus mutans. J Oral Microbiol 2014; 6. Available from: http://www.journaloforalmicrobiology.net/index.php/jom/article/view/24878 [http://dx.doi.org/10.3402/jom.v6.24878] [PMID: 25317251]

Received: April 8, $2015 \quad$ Revised: January 28, $2016 \quad$ Accepted: February 11, 2016

(C) Kishimoto et al.; Licensee Bentham Open.

This is an open access article licensed under the terms of the Creative Commons Attribution-Non-Commercial 4.0 International Public License (CC BY-NC 4.0) (https://creativecommons.org/licenses/by-nc/4.0/legalcode), which permits unrestricted, non-commercial use, distribution and reproduction in any medium, provided the work is properly cited. 